\title{
Advanced Doubly Fed Induction Machine Rotor Fault Diagnosis Based on Wavelet Analysis in Closed-Loop Operation Under Time-varying Condition
}

\author{
Y. Gritli ${ }^{1,2}$, A. Stefani ${ }^{2}$, C. Rossi ${ }^{2}$, F. Filippetti ${ }^{2}$ and A. Chatti ${ }^{1}$ \\ ${ }^{1}$ National Institute of Applied Sciences and Technology \\ I.N.S.A.T., $7^{\text {th }}$ November University at Carthage, Tunis (Tunisia) \\ Phone number: +216 71703717 - p.6057/6056 \\ e-mail: yasser.gritli@esti.rnu.tn, abderrazak.chatti@insat.rnu.tn \\ ${ }^{2}$ University of Bologna, Department of Electrical Engineering Bologna (Italy) \\ Phone/Fax number: +39 0512093564 / +39 0512093588 \\ e-mail: andrea.stefani@mail.ing.unibo.it, claudio.rossi@ mail.ing.unibo.it, \\ fiorenzo.filippetti@mail.ing.unibo.it
}

\begin{abstract}
This paper introduces a new diagnostic technique for the detection of incipient electrical rotor faults in doubly fed induction Machine (DFIM) for wind power systems. In the considered application, the rotor is supplied by a static converter for the control of active and reactive power flows from the generator to the electrical grid. A new diagnostic method based on the rotor modulating signals pre-processing by Frequency Sliding (FS) and Discrete Wavelet Transform (DWT) thereby is here proposed to detect rotor faults dynamically over time. Experimental and simulation results demonstrate the effectiveness of the proposed approach under time-varying conditions.
\end{abstract}

\section{Key words}

Doubly Fed Induction Machine (DFIM), rotor fault, Sliding Frequency (SF), Wavelet decomposition.

\section{Introduction}

Wind power generation has become the most accessible and efficient form of renewable energy during the past few years. Wind turbines equipped with Doubly Fed Induction Machine (DFIM) are emerging as the preferred technology in the field. Among different alternatives and for Variable Speed Constant Frequency (VSCF) generation systems, the DFIM can provide higher energy output with lower rating of power converter. Particularly in this type of application, monitoring the induction machine is crucial to ensure safe operation, timely maintenance and increased operation reliability for extracting the maximum of the wind energy. A recent study [1] has revealed that $13 \%$ of wind turbine failures are related to the motor. Investigations on different failure modes in induction motors have revealed that $19 \%$ of the overall motor faults are related to the rotor part [2]. A detailed analysis of this type of fault can be found in [3]. Different diagnostic methods have been proposed for wind turbines using DFIM [4]-[6]. Depending on wind speed, the induction machine operates continuously in time-varying condition. In this context, the classical application of Fourier Analysis (FA) for processing manipulated (voltages) or controlled (currents) variables fails as slip and speed vary. Thus the fault components are spread in a bandwidth proportional to the variation. Among different solutions, high resolution frequency estimation [7] and more recently Signal Demodulation (SD) technique [8] have been developed to reduce the effect of the non periodicity on the analyzed signals. These techniques, based on (FA) give high quality discrimination between healthy and faulty conditions but don't provide time domain information. Wavelets, on the other hand, provide greater resolution in time for high frequency components of a signal and greater resolution in frequency for low frequency components. This method has been used with different approaches for the diagnosis of anomalies in induction machine [9]-[12]. Most of the reported contributions are based on the wavelet analysis of currents during start-up or load variation for diagnosis purposes. In this context, the frequency components are spread in a wide bandwidth as slip and speed vary considerably. This fact justifies the common use of multidetail or/and approximation signals resulting from wavelet decomposition, whose levels are imposed by the sampling frequency. This dependency on the appropriate choice of the sampling frequency and tracking multi fault frequency components on multi frequency bands complicate the diagnosis process. Moreover, the use of large frequency bands subjects the detection procedure to erroneous interpretations due to possible confusion with other harmonics due to the use of gearboxes [13], commonly used in wind turbines. Motivated by the above discussion, a new monitoring and diagnostic technique based on frequency sliding and DWT thereby, has been investigated in open-loop operation and experimentally validated [14]-[15]. Obviously in open-loop case, rotor voltages have no values due to the short circuited rotor windings. In closed-loop drives, the control itself has an 
impact on the relevance of fault frequency components on both manipulated (voltages) and controlled (currents) variables [16]. In this paper, rotor currents and voltages will be analysed to evaluate this impact in time-varying condition and to prove the robustness of the proposed technique in discriminating healthy from faulty rotor in DFIM.

\section{Control System Description}

For a DFIM associated with a back-to-back PWM converter on the rotor side and with the stator directly connected to the grid, a stator flux oriented vector control is utilized in order to control separately the active and reactive power on the stator side. The relationships between the active and reactive stator power and the rotor current components are [5]:

$$
\begin{aligned}
& P_{s} \cong-\frac{3}{2} \cdot\left|\overline{v_{s}}\right| \cdot \frac{L_{m}}{L_{s}} i_{q r} \\
& Q_{s} \cong \frac{3}{2} \cdot\left|\overline{v_{s}}\right| \cdot \frac{L_{m}}{L_{s}}\left(\frac{\left|\overline{v_{s}}\right|}{2 \pi f_{s} L_{m}}-i_{d r}\right)
\end{aligned}
$$

Where $L_{s}$ and $L_{m}$ are the stator inductance and the magnetizing inductance respectively. Equations (1) and (2) show the possibility to realize a decoupled power control. In fact the stator active power is in inverse proportion with the quadrature rotor current $i_{q r}$, and that the stator reactive power is in inverse proportion with the direct rotor current $i_{d r}$, being the stator voltage and frequency $\left|v_{s}\right|$ and $f_{s}$ imposed by the grid.

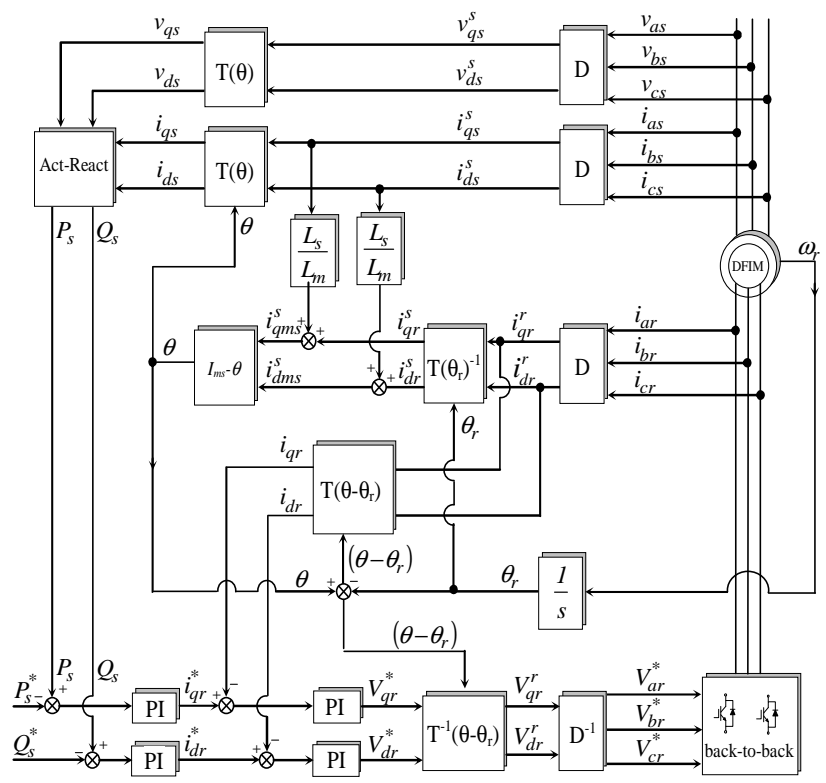

Fig. 1. Block scheme of the whole control system

As shown in Fig. 1. the DFIM control system is based on two cascaded loops. The outer loop is dedicated to the stator active and reactive power control, whereas the inner one is related to the direct and quadrature rotor current components. The blocks containing $D$ and $D^{-1}$ represents respectively the Clarke's and the inverse Clarke's transformations from a three phase to a two phase dq system. On the other hand those containing $T(\theta), T\left(\theta-\theta_{r}\right), T^{l}(\theta), T^{l}\left(\theta-\theta_{r}\right)$ represents the reference frame transformations respectively from stationary (stator) to synchronous, from rotating (rotor) to synchronous and their inverse, being $\theta$ and $\theta_{r}$ the stator flux phase angle and the rotor position angle respectively. The control algorithm uses the components of the magnetizing current space vector [5] to compute the phase $\theta$ of the stator flux vector by means of the following equation:

$$
\theta=\arctan \left(\frac{i_{q m s}}{i_{d m s}}\right)
$$

Moreover in order to increase the accuracy in the angle computation a complex digital filter was applied to the magnetizing current components in the stator reference frame $i_{q m s}$ and $i_{d m s}$ appearing in the equation (3). On the other hand the rotor position angle $\theta_{r}$ is retrieved thanks to an incremental encoder present in the control system.

\section{Rotor fault frequency tracking - The proposed approach}

The principal feature of wavelet analysis is its High Multiresolution Analysis HMRA capability. Wavelet analysis is signal decomposition, using successive combination of approximation and detail signals. The procedure is repeated until the original signal is decomposed to a pre-defined J level decomposition [17]. With the well known dyadic down sampling procedure, frequency bands of each level of decomposition are related to the sampling frequency. Hence, these bands can't be changed unless a new acquisition with different sampling frequency is made. This fact complicates any fault detection based on DWT, particularly in timevarying condition. In this paper, an efficient solution to overcome this limitation is proposed. With a sampling frequency $f_{s}=3.2 \mathrm{kHz}$, an eight level decomposition $(J=8)$ was chosen in order to cover the frequency bands in which we can track frequency component characteristics of the fault (see Table I).

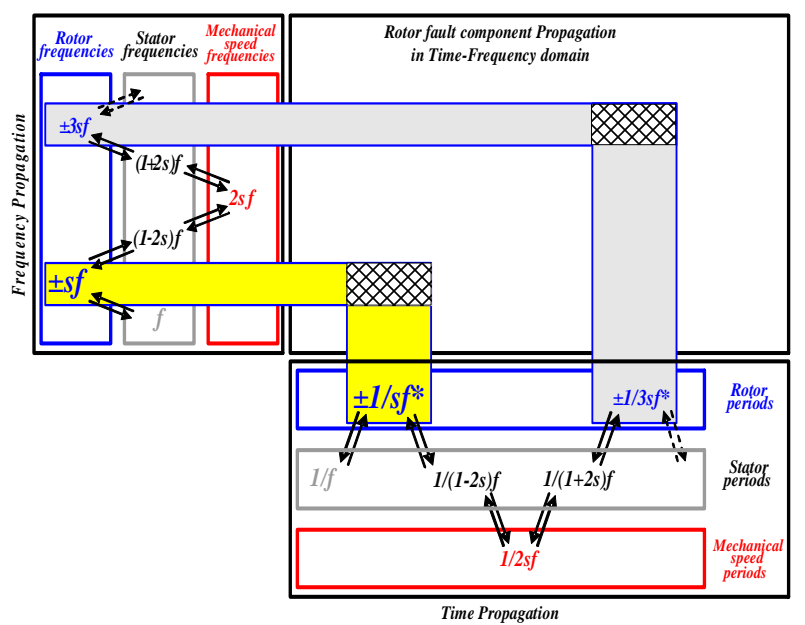

Fig. 2 Time-Frequency propagation of a rotor fault: the sign (-) in time domain is corresponding to the inverse current sequence component.

Under healthy conditions, only the fundamental frequencies $s f$ exist on rotor currents and voltages $(f$ : 
supply frequency, $s$ : slip). Observing the time-frequency propagation of a rotor fault illustrated in Fig. 2, the first fault frequency component that occurs in the rotor currents and voltages is $-s f$. Neglecting other effects like slotting and saturation, it can be assumed that the major components of the rotor current and voltage space vectors can be written respectively as:

$i_{r}(t)=\sqrt{3}\left[I e^{j \omega_{r} t}+I_{-s f} e^{j\left(\omega_{-s f} t-\varphi_{-s f}\right)}+I_{3 s f} e^{j\left(\omega_{3 s f} t-\varphi_{3 s f}\right)}\right](4)$

$\underline{V}_{r}(t)=\sqrt{3}\left[V e^{j \omega_{r} t}+V_{-s f} e^{j\left(\omega_{-s f} t-\varphi_{-s f}\right)}+V_{3 s f} e^{j\left(\omega_{3, f} t-\varphi_{3, f}\right)}\right](5)$

Where $I$ and $V$ are the rms values of the fundamental component, $\left(I, V_{\text {sf }}\right.$ and $\left.I, V_{3 s}\right)$ are those relatively to the first and second level of fault harmonic components $\omega_{-s f}=-s \omega$ and $\omega_{3 f}=3 s \omega$. In time varying conditions the magnitudes $I_{s f}, V_{s f}, I_{3 s f}$ and $V_{3 s f}$ can't be detected through a frequency analysis since $\omega_{-s f}$ and $\omega_{3 s f}$ are spread in a wide frequency range.

A simple processing of the rotor current space vector, allows shifting the fault component $-s f$ to a desired prefixed frequency band. In such a way, all the information related to the fault is isolated and confined in a single frequency band. More in detail, a frequency sliding with $f_{s l}$ is applied at each time slice to the rotor current and voltages space vectors as in (6), so that the harmonic component of interest is moved to the desired frequency band. Then the real part of the shifted signal is analyzed by means of DWT.

$$
I, V_{s l}(t)=\operatorname{Re}\left[\underline{i}_{r}, \underline{V_{r}}(t) e^{-j 2 \pi f_{s l} t}\right]
$$

The choice of $f_{s l}$ is done for shifting the fault frequency component in one of the intervals $\left[0: 2^{-(J+1)} \cdot f_{s}\right]$ or $\left[2^{-(J+1)} \cdot f_{s}: 2^{-J} \cdot f_{s}\right]$ and subsequently the DWT is applied to analyze the frequency band of interest. The proposed approach was applied to the rotor current and voltages space vectors with $f_{s l}=-8.5 \mathrm{~Hz}$, to isolate the contribution of the $-s f$ component. Hence, with respect to the frequency bands reported in Table I, the frequency band of interest, for tracking the $-s f$ frequency contribution is the $8^{\text {th }}$ DWT level decomposition.

Table I. - Frequency Band of each level

\begin{aligned} \hline Approximations & Frequency & $\begin{array}{r}\text { Details } \\ \ll d_{j} »\end{array} & \begin{array}{l}\text { Frequency } \\ \text { bands }(\mathrm{Hz})\end{array} \\$\hline$a_{j} » &$ Bands $(\mathrm{Hz}) & d_{8} & :[6.25-12.5] \\ a_{8} & :[0-6.25] & d_{7} & :[12.5-25] \\ a_{7} & :[0-12.5] & d_{6} & :[25-50] \\ a_{6} & :[0-25] & d_{5} & :[50-100] \\ a_{5} & :[0-50] & d_{4} & :[100-200] \\ a_{4} & :[0-100] & & \end{aligned}$

\section{Rotor fault analysis under speed-varying condition}

\section{A. Simulation results}

In order to validate the applicability of the proposed diagnostic approach, several simulations, under healthy and faulty rotor conditions, were conducted. Rotor unbalance was emulated by inserting an additional resistance Radd in series with one rotor phase winding.

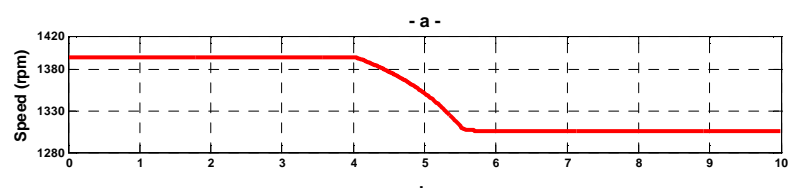

- b -

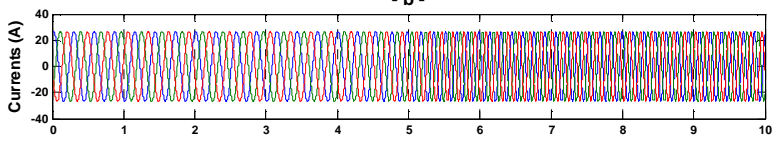

c-

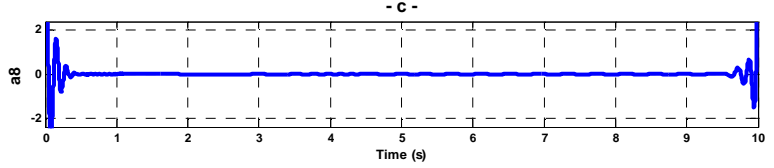

Fig. 3. DWT of the rotor current $I_{s l}$ in healthy condition $($ Radd $=0)$ under speed transient. Simulation results

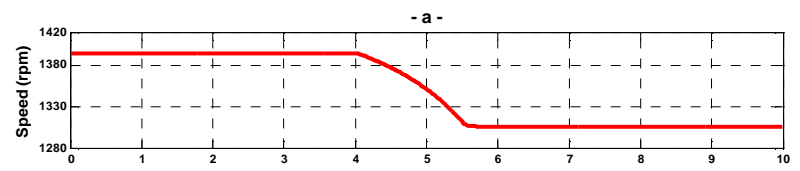

- b -
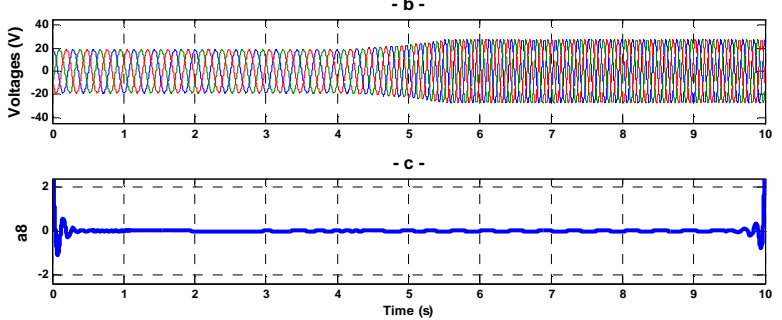

Fig. 4. DWT of the rotor voltage $V_{s l}$ in healthy condition $($ Radd $=0)$ under speed transient. Simulation results

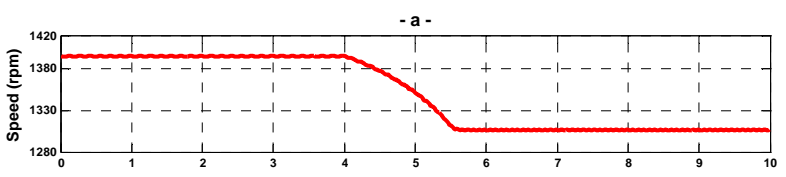

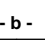

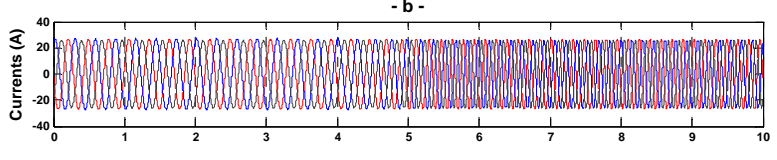
c-

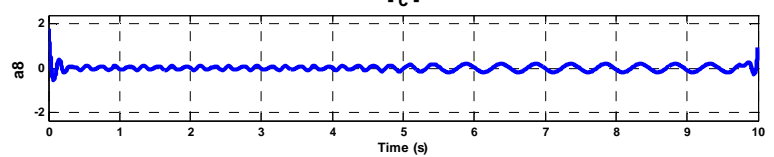

Fig. 5. DWT of the rotor current $I_{s l}$ in faulty condition (Radd=Rr) under speed transient. Simulation results
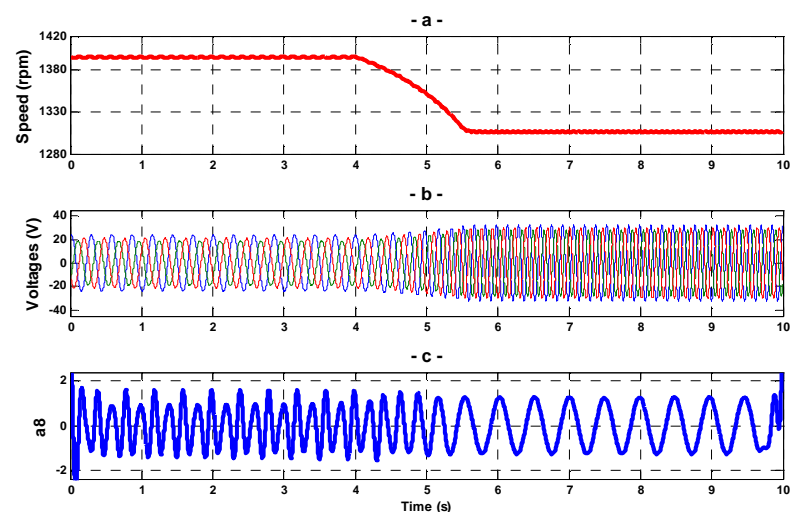

Fig. 6. DWT of the rotor voltage $V_{s l}$ in faulty condition (Radd=Rr) under speed transient. Simulation results 
The controlled machine has been initially simulated in healthy condition $(\operatorname{Radd}=0)$, with a bandwidth of the current loop equal to $\mathrm{Bp}=100 \mathrm{~Hz}$ and with the generator delivering an active power of $5500 \mathrm{~W}$ and absorbing a reactive power of $4100 \mathrm{VAR}$ from the stator side, during a prefixed transient from $1395 \mathrm{rpm}$ to $1306 \mathrm{rpm}$. All signals reported have been recorded during 10 seconds. As explained in the previous section, the contribution of the fault frequency components $-s f$ will be observed on approximation $a_{8}$ after a suitable frequency sliding applied to the rotor current and then the voltage space vectors.

The wavelet decompositions of the $I_{s l}$ and $V_{s l}$ signals, in healthy condition during deceleration, are used as a reference in comparison with the faulty case. In Fig. 3-c and Fig. 4-c, the $8^{\text {th }}$ approximation signal (relatively to $\mathrm{I}_{\mathrm{sl}}$ and $\mathrm{V}_{\mathrm{sl}}$ ) for healthy machine is depicted. It is possible to notice that no effect on these signals, during the speed transient, has been registered. In faulty condition (Radd=Rs), the contribution of the $-s f$ component, observed on the $8^{\text {th }}$ approximation signal, is more relevant for the rotor voltages (Fig.6-c) than the corresponding one to the rotor current (Fig.5-c).The loss of relevance observed on rotor currents is mainly due to the damping effect of the control system imposed by the bandwidth of the current loop.

\section{B. Experimental results}

In order to validate the results obtained in simulations, a test bed was realized. A $5.5 \mathrm{~kW} 2$ poles pair wound rotor induction machine (see Appendix) was connected with a PWM back to back converter on the rotor side (see Appendix). The direct field oriented control for the DFIM was implemented on a dSPACE DS1103 board. The generator was coupled with a $9 \mathrm{~kW}$ DC motor fed by a commercial DC/DC chopper converter controlled in speed used to test and reproduce the simulated speed transients.
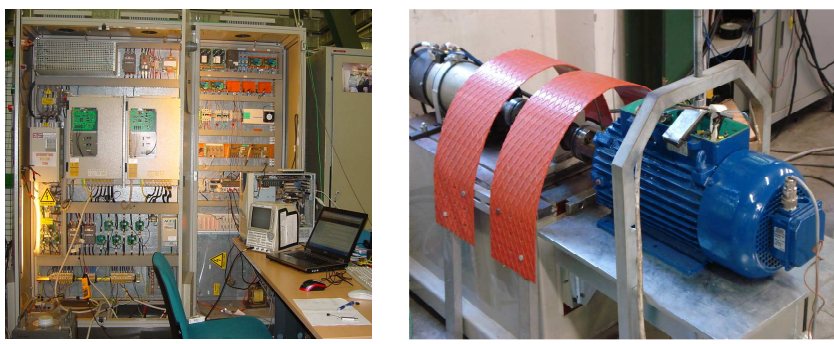

Fig. 7 Experimental test bed photos

Experimental test bed photos are illustrated in Fig. 7. For the study of the phenomena caused by a rotor fault, an external resistance Radd has been inserted in series to one rotor phase in order to emulate rotor asymmetry. Experimental results under healthy and faulty conditions $(R a d d=R r)$ are reported from Fig. 8 to Fig. 11. These results corroborate simulations although the magnitude evolutions in some cases are even bigger than in simulation.

The $8^{\text {th }}$ approximation signal obtained from the experimental results show the sensitivity and the effectiveness of this particular approximation signal to reproduce the contribution of the frequency component $s f$ under rotor unbalance.

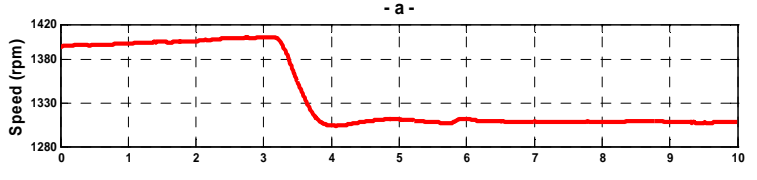

- b -
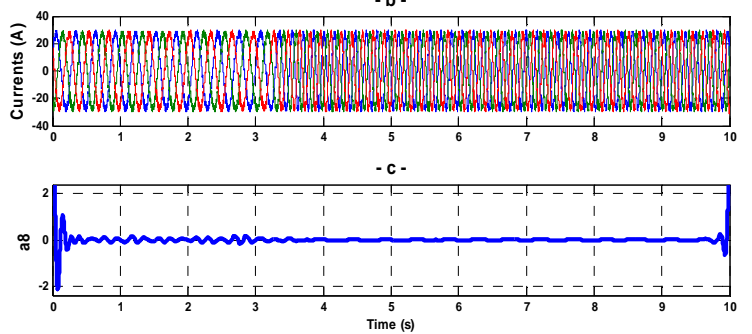

Fig. 8. DWT of the rotor current $I_{s l}$ in healthy condition $(\mathrm{Radd}=0)$ under speed transient. Experimental results

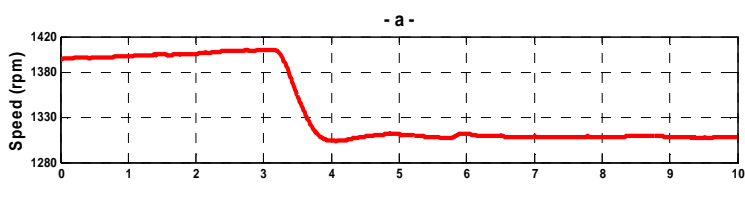

- b -
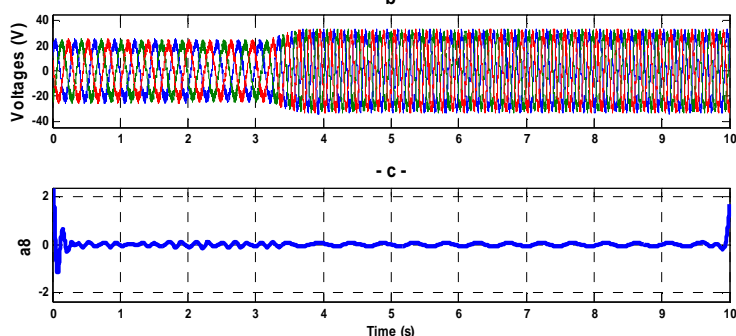

Fig. 9. DWT of the rotor voltage $V_{s l}$ in healthy condition $($ Radd $=0)$ under speed transient. Experimental results

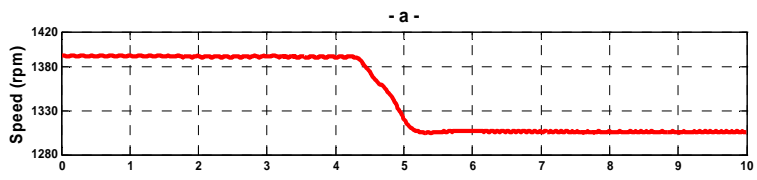

b -

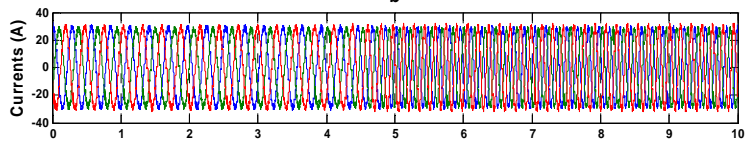

c.

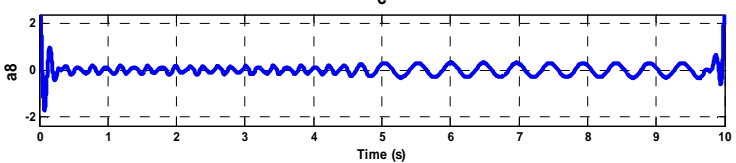

Fig. 10. DWT of the rotor current $I_{s l}$ in faulty condition (Radd=Rr) under speed transient. Experimental results

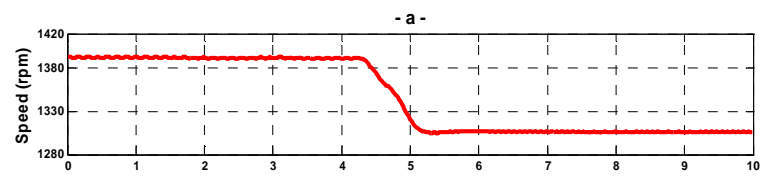
- b -
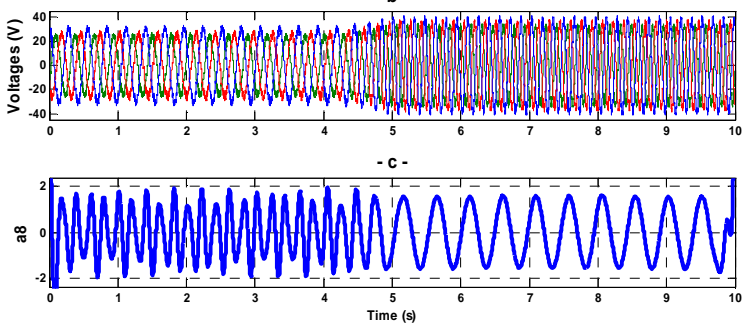

Fig. 11. DWT of the rotor voltage $V_{s l}$ in faulty condition (Radd=Rr) under speed transient. Experimental results 


\section{Quantitative rotor fault evaluation}

Once the state of the machine has been qualitatively diagnosed, a quantitative evaluation of the fault degree is necessary. For these purposes a dynamic multiresolution mean power indicator $m P a_{j}$ at different resolution levels $j$ was introduced as a diagnostic index to quantify the extent of the fault as in (7):

$$
m P a_{j}(I, V)=\frac{1}{N} \sum_{n=1}^{N}\left|a_{j}(n)\right|^{2}
$$

Where $N$ is the number of samples and $j$ is the level decomposition. In this way, for $J$ level wavelet decomposition, we construct a $J$ dimensional feature vector for future analysis. Since the most relevant fault frequency component is the $-s f$ only its contribution clamped in the $8^{\text {th }}$ approximation $a_{8}$ was adopted to quantify the extent of the fault.

Other fault components could be treated in the same way but they are neglected because of the damping effect of the machine load and inertia on higher order fault harmonics. This choice reduces the feature dimension and consequently the computational time.

The fault indicator is periodically calculated (every 400 samples) using a window of 1600 samples as depicted in Fig. 12 where $\delta n=400$ samples and $\Delta n=1600$ samples.

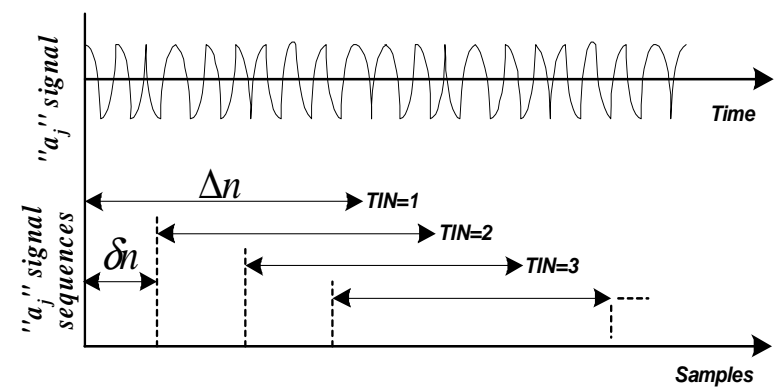

Fig. 12. Principle of time interval calculation, TIN: Time Interval Number

These values were regulated experimentally to reduce variations that can lead to false alarm in healthy operating conditions of the motor. When the fault occurs, the energy distribution of the signal is changed at the resolution levels related to the characteristic frequency bands of the default. Hence, the energy excess confined in the approximation is considered as an anomaly indication in case of rotor faults.

The mean power of the approximation $\mathrm{a}_{8}$ resulting from the wavelet decomposition applied to rotor currents and voltages, which have been obtained from simulations (Fig. 3 and Fig. 5) are depicted in Fig.13-a and Fig.13-b respectively. In healthy conditions $(\operatorname{Rad} d=0)$ and under large range of speed variations, the calculated $\mathrm{mPa}_{8}(I, V)$ indicators don't show any significant changes. Consequently, the indicator values for the healthy motor response are considered as a baseline to set the threshold for discriminating healthy from unbalanced rotor conditions.In faulty conditions $(R a d d=R r)$ the calculated $m \mathrm{~Pa}_{8}(\mathrm{I})$ indicator (Fig. 13-a) don't show significant increase. As previously discussed, this is due to the damping effect of the control system. However, the calculated $\mathrm{mPa}_{8}(\mathrm{~V})$ indicator (Fig. 13-a) show significant increase. The large energy deviation observed in faulty conditions prove the effectiveness of the proposed approach, since the speed motor operation does not disturb the assessment with respect to the case of a healthy machine. Experimental results under healthy and faulty conditions $(\operatorname{Rad} d=R r)$ are depicted in Fig. 14. The slight oscillation observed on the fault indicator in Fig. 13-b and Fig. 14-b comes from the proximity of the fault frequency $-s f$ to the fundamental one $s f$ of the rotor voltages. This fact together with the intrinsic overlapping effects of wavelet transformation causes this oscillation. Anyway the results that have been obtained experimentally corroborate simulations although the magnitude evolutions in some cases are even bigger than in simulation, thus proving the effectiveness of the proposed time-frequency rotor fault indicator.
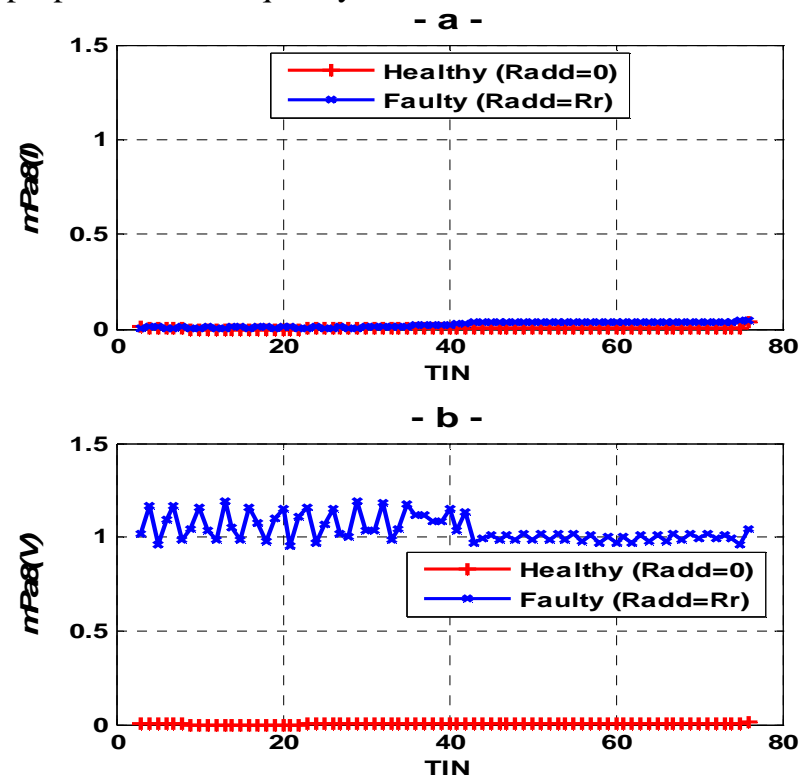

Fig. 13. Mean power of the approximation a8 resulting from the wavelet decomposition of the signals $I_{s l}(-\mathrm{a}-)$ and $V_{s l}(-\mathrm{b}-)$ under deceleration transient. Simulation results.
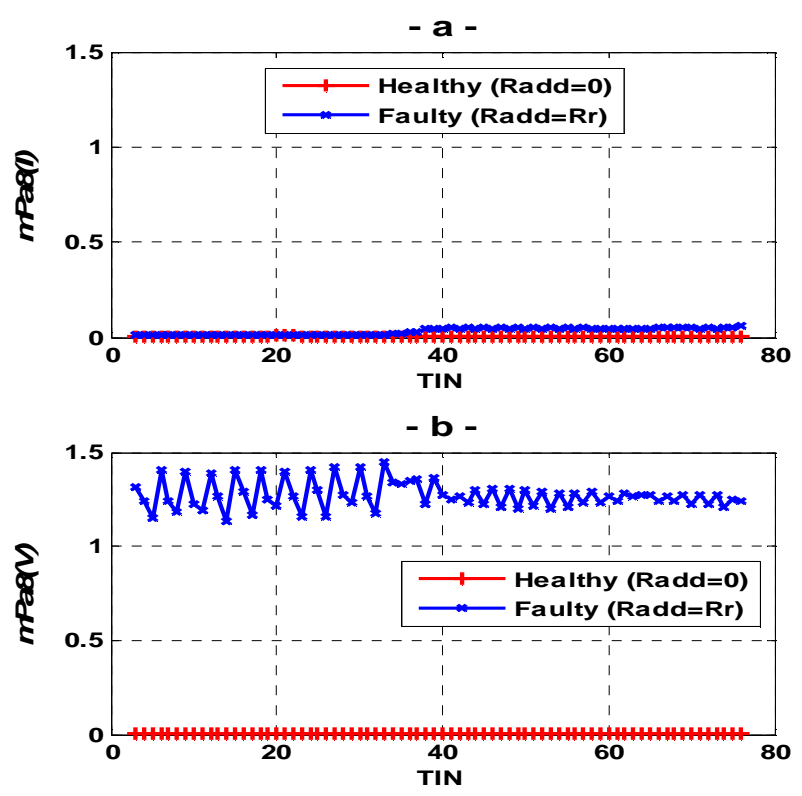

Fig. 14. Mean power of the approximation $a_{8}$ resulting from the wavelet decomposition of the signals $I_{s l}(-\mathrm{a}-)$ and $V_{s l}(-\mathrm{b}-)$ under deceleration transient. Experimental results. 


\section{Conclusion}

The aim of this paper was to validate the effectiveness of a new and reliable approach for the characterization of rotor fault in time varying condition.The proposed approach is based on an optimized use of the DWT by a simple pre-processing of the variables to be analyzed. Results prove that for closed loop condition and under a rotor unbalance, rotor voltages are more sensitive than rotor currents. These results show the limits of the current signature analysis under time-varying conditions. A dynamic time-frequency fault indicator is presented to quantify the fault extent. Simulation and experimental results carried out, demonstrate the effectiveness of this new approach that can be applied to any type of machine and extended for diagnosing other types of faults under time-varying conditions.

\section{APPENDIX}

Induction Motor Parameters

\begin{tabular}{lrr}
\hline Parameter & \multicolumn{2}{c}{ Value } \\
\hline Rated Power & $\mathrm{kW}$ & 5.5 \\
Rated stator/ & $\mathrm{V}$ & 380 \\
rotor voltage & $\mathrm{V}$ & 186 \\
Rated frequency & $\mathrm{Hz}$ & 50 \\
Rated speed & $\mathrm{rpm}$ & 1400 \\
Stator phase resistance & $\Omega$ & 0.531 \\
Rotor phase resistance & $\Omega$ & 0.310 \\
Stator inductance & $\mathrm{H}$ & 0.083 \\
Rotor inductance & $\mathrm{H}$ & 0.019 \\
Mutual inductance & $\mathrm{H}$ & 0.038 \\
Pole pairs & & 2 \\
\hline
\end{tabular}

Back-to-Back Converter

\begin{tabular}{lrr}
\hline Parameter & \multicolumn{2}{c}{ Value } \\
\hline Gride side converter & & \\
switching frequency & $\mathrm{kHz}$ & 10 \\
Rotor side converter & & \\
switching frequency & $\mathrm{kHz}$ & 12 \\
Gride voltage & $\mathrm{V}$ & 400 \\
Gride coupling & & \\
inductance & $\mathrm{mH}$ & 1.2 \\
DC-Link voltage & $\mathrm{V}$ & 500 \\
Encoder type & $\mathrm{Imp} / \mathrm{tun}$ & 1024 \\
\hline
\end{tabular}

\section{References}

[1] F. Ciamberlano, J. Nitschke, N. Kragelund, J. Thiede, M. Fusselbaugh, M. Johst, F.V. Velde, "Engineering Insurance of Offshore Wind Turbines", 39th IMIA Annual Conference on Sept. 2006 in Boston.

[2] A.H. Bonnett, C. Yung,, "Increased Efficiency Versus Increased Reliability", IEEE Ind. App. Mag., Vol. 14, Issue 1, Jan./Feb. 2008

[3] A. Bellini, F. Filippetti, C. Tassoni, and G. A. Capolino, "Advances in diagnostic Techniques for induction machines", IEEE Tran. on Ind. Elec., Vol.55, $\mathrm{N}^{\circ} 12$, Dec. 2008.

[4] V. Dinkhauser, F.W. Fuchs, "Rotor turn-to-turn faults of doubly-fed Induction generators in wind energy plants- modelling, simulation and detection", $13^{\text {th }}$ EPE-PEMC'08, pp. 1819-1826, Sept. 2008.

[5] A. Stefani, A. Yazidi, C. Rossi, F. Filippetti, D. Casadei and G.A. Capolino, "Doubly Fed Induction Machines Diagnosis Based on Signature Analysis of Rotor Modulating Signals", IEEE Trans. on Indus. Appl., Vol. 44, $\mathrm{N}^{\circ}$ 6, Nov/Dec 2008.

[6] Y. Gritli, A. Stefani, F. Filippetti and A. Chatti, "Stator fault analysis based on Wavelet technique for wind turbines equipped with DFIG", ICCEP'09, pp 485-491. Italy, June 2009.

[7] Kia, S.H.; Henao, H.; Capolino, G.-A., "A HighResolution Frequency Estimation Method for Three-Phase Induction Machine Fault Detection", IEEE Tran. Ind. Elec, Vol. 54, Issue 4, pp. 2305 - 2314, Aug. 2007.

[8] A. Stefani, F. Filippetti, A. Bellini, "Diagnosis of Induction Machines in Time-varying Conditions", IEEE Trans. on Ind. Appl., Vol. 56, N 11, Nov. 2009.

[9] S. Rajagopalan, J.M. Aller, J.A. Restrepo, T.G. Habetler, R.G. Harley, "Analytic-Wavelet-Ridge-Based Detection of Dynamic Eccentricity in Brushless Direct Current (BLDC) Motors Functioning Under Dynamic Operating Conditions", IEEE Trans. on Ind. Elec, Vol. 54, $\mathrm{N}^{\circ} 3$, pp. 1410-1419, June 2007.

[10] A. Ordaz-Moreno, R.J.Romero-Troncoso, J. A. Vite-Frias, J. R. Rivera-Gillen, and A. Garcia-Perez, "Automatic Online Diagnosis Algorithm for Broken-Bar Detection on Induction Motors Based on Discrete Wavelet Transform for FPGA Implementation", IEEE Trans. on Ind. Elec., Vol. 55, $\mathrm{N}^{\circ}$ 5, pp. 1361-1368, May. 2008.

[11] J. Cusido, L. Romeral, J.A. Ortega, J.A. Rosero, A. G. Espinosa, "Fault Detection in Induction Machines Using Power Spectral Density in Wavelet Decomposition", IEEE Trans. Ind. Elec., Vol. 55, N 2, pp. 633-643, Feb. 2008.

[12] J.A. Daviu, P.J. Rodriguez, M.R. Guasp, M. P. Sanchez, A. Arkkio, "Detection of combined faults in induction machines with stator parallel branches through the DWT of the start-up current", Journal of Mechanical Systems and Signal Processing, accepted in Feb. 2009.

[13] W.T. Thomson and M. Fenger, "Current Signature Analysis to Detect Induction Motor Faults", IEEE Industry Applications Magazine, pp. 26-34, July/August 2001.

[14] Y. Gritli, A. Stefani, C. Rossi, F. Filippetti and A. Chatti, "Doubly Fed Induction Machine Stator fault Diagnosis Under Time-Varying Conditions Based on Frequency Sliding and Wavelet Analysis", IEEE-SDEMPED'09. Cargese-France, Aug./Sep. 2009.

[15] Y. Gritli, A. Stefani, A. Chatti, C. Rossi and F. Filippetti, " The Combined use of the Instantaneous Fault Frequency Evolution and Frequency Sliding for Advanced Rotor Fault Diagnosis in DFIM Under Time-Varying Condition", IECON'09. Porto-Portugal, Nov. 2009.

[16] D. Casadei, F. Filippetti, C. Rossi and A. Stefani, "Closed Loop Bandwidth Impact on Doubly Fed Induction Machine Asymmetries Detection Based on Rotor Voltage Signature Analysis", $43^{\text {rd }}$ UPEC'08, Padova-Italy, Sept. 2008.

[17] T.K. Sarkar, C. Su, R. Adve, M.S. Palma, L.G. Castillo, R. Boix, "A Tutorial on Wavelets from an Electrical Engineering Perspective, Part 1: Discrete Wavelet Techniques", IEEE Ante. and Prop. Mag., Vol. 40, $\mathrm{N}^{\circ}$ 5, Oct. 1998. 